\title{
Histological Changes in Human Gallbladder in Pathological Condition Including Cholecystitis and Cholelithiasis an Analytical Study
}

\author{
Dr JyotiPrakash Pani ${ }^{1}$, Mr Shubham Pandey ${ }^{2}$, Dr Sankarsan Pani ${ }^{2}$, Dr \\ G.N.Geetha ${ }^{2}$, Dr M N Mahendrakar ${ }^{2}$, Dr Karuna H. Katti ${ }^{2}$ \\ ${ }^{1}$ (Department of Anatomy, Institute of Medical Sciences Varanasi, UttarPradesh 221005/ Banaras Hindu \\ University, India,) \\ ${ }^{2}$ (Department of Biostatistics, Institute of Medical Sciences Varanasi Uttar Pradesh 221005/Banaras Hindu \\ University, India) \\ ${ }^{2}$ (Department of Surgery, M.G.M. Medical College, Kamothe, Kalamboli/M.G.M.University of Health and \\ Sciences Navi Mumbai, India)
}

\begin{abstract}
Present study compares histological changes in the wall of diseased human gall bladder like cholelithiasis\&cholecystitis and find out the risk factors for the formation of gall stone in gallbladder. To conduct case control study, 60 normal (control group) human gallbladders \& 30 abnormal (case group) samples having cholelithiasis and cholecystitis were obtained and processed. After proper processing, from each sample 3 slides were stained by H\&E stain, Combined PAS-AB stain \& Sudan Black B stain respectively for routine histochemistry, mucin histochemistry\& lipid histochemistry study. Different histological findings were noted in the various layers of gallbladders. Epithelial hyperplasia, dysplasia with erodification of mucosa and sub epithelial haemorrhages was denoted in both cholelithiasis\&cholecystitis. On the behalf of statistical evidence, the present study shows both group case and control are highly significant. Sulfomucin is predominant variable for cholelithiasis $(P$ value 0.000$)$ and sailomucin is predominant variable for cholecystitis ( $P$ value 0.0065).The Relative Risk of sulfomucin present or not present was 193:1(odd ratio) and the relative risk for sailomucin present or not present in cholecystitis was 105:1(odd ratio).The basic principle in gall stone formation is accumulation of lipids and hyper secretion of acidic mucin particularly sulfomucin. They alter the normal tissue pattern \& can induce carcinogenic progression \& metastasis. Blockage or inhibition of acid mucin release can prevent gall stone formation or the compounds which regulate sailylation and sulfation might help to inhibit gall stone formation \& metastasis. Scope of this research is prevention is better than cure.
\end{abstract}

KEYWORDs: Acidic mucin, epithelial lipid, immunohistochemistry, neutral mucin, RokitanskyAschoff Sinus

\section{I. .INTRODUCTION}

"Gallbladder diseases like cholecystitis and cholelithiasis are very common particularly in fatty, fertile \& female of fortyto fifty but equally affects male and children. ${ }^{[1]}$ Cholecystitis and cholelithiasis appear to be increasing in incidence over past couple of decades in India and western world due to increased intake of fatty and high calorie diet and increased consumption of alcohols. ${ }^{[2,3]}$

1.1."Anatomy of normal gall bladder"The fossa for the gallbladder extends from the right end of the portahepatis to the inferior border of the liver. ${ }^{[4]}$ It is 7 to $10 \mathrm{~cm}$ ( 3 to 4 inches) long. $3 \mathrm{~cm}$ broad at its widest part and about 30 to $50 \mathrm{mlin}$ capacity. ${ }^{[5]}$ It is divisible into fundus, body and neck. ${ }^{[6]} \mathrm{Neck}$ is continues as cystic duct $\&$ is marked by a constriction. Histologically it shows 4 layer's and lacksmuscularis mucosa. ${ }^{[7]}$ It shows inside out, mucosal layer, loose sub mucosa, muscle layer and adventitial (serosal) layer. Incholecystitis and cholelithiasis the wall of human gallbladder shows, certain histological changes. The present study is carried out to find out the same. ${ }^{[8-10]}$

1.2."'Review of literature"Over 100 years ago Virchow R., in 1857 found that lipids can accumulate in gallbladder epithelium.$^{[11]}$ Storey GW, Sheean H, in 1947 studied an improved method of staining leukocyte granule with Sudan black B. ${ }^{[12]}$ Wallraff J, Dietrich KF in 1957 found lipid in the human gallbladder mucosa in the patient with chronic cholecystitis. ${ }^{[13]}$ Schwartz SI, Dale WA in 1958 studied primary sclerosing cholangitis and found coexistence of inflammatory lesions in the gall bladder, abundance of lymphocyte and plasma cells in the sub mucosa with those present in the bile duct.

This is usually associated with cholecystitis in which abundance of lymphoid follicles \& moderate to severe chronic inflammatory cells were found ${ }^{[14]}$ Thorpe MEC, Scheurer PJ, Sherlock S et al in 1967 studied 
primary sclerosing cholangitis in biliary tree \& ulcerative colitis and got the same finding as above. ${ }^{[15]}$ Hopwood D, Kouroumalis E, Milne G, Bouchier IAD et al in 1980 studied cholecystitis and found the presence of various lipids in the wall of the gall bladder with marked increase in the neutral lipid in the sub mucosa in severe cholecystitis. Inflammatory cells including macrophages may contain at least a portion of this lipid. ${ }^{[16]}$ Stevens A, Baylis H OB. Lipids. In. Bancroft JD, et al in 1982 studied 70 cholecystitis gall bladders for lipids in their epithelium. ${ }^{[17]}$ - Smith BF, Moore JRL, Lamont JT, et al in 1984 studied role of gall bladder mucin in pathophysiology of gall stone found in human \& other mammals. The epithelium is able to secrete altered mucus \& these secretory products interact with bile \& potentiate the cholesterol nucleating process. It progresses from the sludge to the production of gall stones. ${ }^{[18]}$ Hopwood D, English M in 1985 studied lipid in human gall bladder mucosa \& found ultra-structural changes in the human cholecystitis. They found some inflammatory changes .Large fatty deposits were demonstrated \& further it was found that the lipid deposits can fuse with mucus containing vesicles to form membrane bound complex structures delineated by a membrane that they called lipomucosomes. Other tissues of the gall bladder wall also increase their fatty deposits. ${ }^{[19]}$ Pearson JF, Foster NE in 1987 found mucus glycoprotein in the human cholesterol gall stones. ${ }^{[20]}$ Tami Yama H, Yamigiwa $\mathrm{H}$ in 1987 studied cholelithiasis\& found dysplasia carcinoma sequence histologically. ${ }^{[21]}$ Afdhal NH in 1990 studied cholesterol crystal nucleation \& found the gall bladder mucus plays a regulatory role in cholelithiasis as it promotes the nucleation of stones. ${ }^{[22]}$ Jeffery GP, Carrelo S, Reed WD et al in 1991 studied histological and immunohistochemical study of the gall bladder lesions in primary sclerosing cholangitis \& found abundance of lymphoid follicles \& plasma cells within sub mucosa \& moderately to severe chronic inflammations were also found. ${ }^{[23]}$ Badke A, Bohm B, Schwenk W, Stock W et al in 1993 studied histological changes in cholelithiasis gall bladder \& found inflammatory changes in some \& fibrotic changes in others. ${ }^{[2]}$ Gilloteaux J, Karkare S, Kelly TR, Hawkins WS et al in 1997 studied structural aspect of human gall bladder in cholelithiasis and found that glycoproteins are responsible for production of stone through biliary sludge ${ }^{[25]}$ Madrid JF, Hernandez F,Ballesta J et al in 1997 studied the characterization of glycoprotein in the epithelial cells of the human and other mammalian gall bladder and found gall stone formation is probably a complex process due to multiple factors. Mucous glycoproteins are one of the factors involved in this process. ${ }^{[26]}$ Csendes A., Smok G., Burdiles P., Diaz J. C., Maluenda F., Korn O. et al in 1998 studied histological findings of gallbladder mucosa in 95 control subjects and with asymptomatic gall stones. Their findings suggest that chronic inflammatory changes can occur in the gall bladder mucosa prior to appearance of macroscopic stones. ${ }^{[27]}$

- Lee KT, Sheen PC, Y: E, Erlia Y et al in 1998 studied mucin content in gall bladder with brown pigment stones or combination stones. Gall bladder mucin itself has been recognised to play the important role in gall stones development. Despite the diverse mechanism of stone induction $\&$ the differences in the stone composition there is quantitative increase in the epithelial mucus production before stone formation. ${ }^{[28]}$ ElgisonDA $^{\mathrm{c}}$, GilloteauxJ ${ }^{\mathrm{a}}$, TommaselloLM ${ }^{\mathrm{b}}$, et al in 2003 studied lipid deposit \& lipid mucosomes in human cholecystitis\& sub structural alteration of human gall bladder deposits. ${ }^{[29]}$ Fusion of lipid deposits and mucous containing vesicles forming complex sub-structural formation called lipomucosomes\&microvillar changes of sparse microvilli \& basal bodies. Small lipid laden structures such as VLDL like vesicles are also fused with mucus vesicles. Epithelial cell sloughing could liberate and add lipomucosomes to the biliary slug and participate in gall stone formation with chronic cholelithiasis. Fatty degeneration of scattered epithelial cells appears to alter the epithelial lining and favour metaplastic changes including carcinoma in situ like lesions. In addition to lipid deposition in macrophages, lipid is also incorporated in other cells \& tissues of gall bladder (endothelium of capillaries), smooth muscles and fibrocytes. Hopwood D, English M in 2005 studied lipid in the human gall bladder mucosa in a histochemical study by light and electron microscopy and found the distribution of lipid in the epithelium of 70 cholecystitis gall bladders. Neutral lipid was found at the base of the epithelial cells in $90 \%$ and at the apex of the epithelial cells and in the underlying connective tissue ${ }^{[30]}$ Halagowder D, Ganesh IM, Duraibabu S et al in 2007 studied mucinglycoarrey in gastric and gall bladder epithelium and discovered mucin as a critical cytoprotective glycoprotein and structural alteration of epithelium due to mucins have been described in different pathological conditions. ${ }^{[31]}$ Ganesh IM, Jaycina M in 2007 studied mucin histochemistry of stone containing gall bladder epithelium. They found mucin play an important role in gall stone formation. ${ }^{[32]}$ Smith BF, Moore JRL, Lamont JT et al in2008 studied role of gall bladder mucin in pathophysiology of gall stone in nucleation. Mucin, a high molecular weight glycoprotein secreted by gall bladder and biliary duct epithelium is a pronucleating agent. ${ }^{[33]}$

\section{AIM AND OBJECTIVES"}

2.1."Aim"The aim of the present study is to compare the histological changes in the wall of human gallbladder in abnormal conditions like cholelithiasis and cholecystitis and to find out the risk factors for the formation of gall stone in gall bladder. 
2.2."Objectives"2.2.1.To find out the histological changes in wall of the gallbladder in above diseases.

2.3.To find out the distribution of neutral and acid mucin in the wall of the gall bladder in cholelithiasis and cholecystitis.

2.4.To find out the distribution of lipids in the wall of the gallbladder in cholelithiasis and cholecystitis.

2.5. The purpose of the study is to correlate the histological alteration with sailylation and sulfation process in the process gall stone formation and its prevention.

2.6.Contribution of the paper" : The concept made in my manuscript was actually a plot revived from the original article of Martin English and David Hop wood on histological changes of human gall bladder of 1985 and the paper of Ganesh IM, Subramani D, HalagowderD.The concept to work on histological changes on human gallbladder was proposed by my supervisor Dr Karuna H. Katti first by the way of applying immunohistochemistry method. She and myself dually planned to do routine

histochemistry,mucinhistochemistry and lipid histochemistry by using H\&E stain,combined PAS-AB stain and Sudan Black B stain and had planned to prepare 3 slides from each total 9 slides for each sample which includes the work of routine histochemistry,mucinhistochemistry and lipid histochemistry.DrKaruna $\mathrm{H}$. Katti, Dr M N Mahendrakar ,Dr G N Geetha collaboratively planned and advised me to procure samples from Dept. of Pathology M.G.M. Medical College and provide me a issue letter.The concept of this manuscript work was to observe histological changes in the wall of human gallbladder after stone formation and what are the histological alteration.Finally to analyze and to compare the effect of neutral mucin with acidic mucin during sulfation and sailylationprocess.DrCharushilaShindhe was appointed as invigilator by my supervisor and my reviewer to cheque daily work done by me and to report them for smooth conduction of the manuscript work which is planned and described in the article.MrsPadmashreeChoughule was appointed as the Senior Lab.Technician to assist and to help me for smooth conduction of the immunohistochemistry work. I took the help of Dept. of Biochemistry, Dept. of Microbiology\& Dept. of Biotechnology for preparation of special stain and to maintain the $\mathrm{Ph}$. of the special stain.So according to my view all my supervisor,reviewer and my reporter including lab. technician had played a tremendous job in order to make the manuscript work successful.I wish them all the best for future.In my view they all have really played the role of guarantor who take all the responsibility to make the project successful.My Supervisor had given me the idea to collect the article.I solely searched all the review of literature,Me and Dr CharushilaShindhe had arranged those review of literature and references in chronological year wise and in alphabetical form.References are arranged in Vancouver system of referencing by me.Finally I had made a decision to publish this manuscript work.

\section{MATERIAL \& METHODS”}

To conduct case control study, 60 normal (control group)human gall bladders and 30 abnormal (case group) samples of human gall bladdershaving cholelithiasis and cholecystitis were obtained from Department of Pathology M.G.M. Medical College,Navi-Mumbai (India) which was kept in 10\% formalin preservative. There were 22 samples of cholelithiasis(Chronic calculus cholecystitis) and 8 samples were of cholecystitis out of which 6 samples were of chronic cholecystitis and 2 samples were of chronic follicular cholecystitis. 44 normal gall bladder samples were selected in contrast to 22 cholelithiasis gall bladder samples and rest of the 16 normal were selected in contrast to 8 cholecystitis gall bladder samples. Male and female normal and diseased human gall bladder were used.The strain was homosapiens. The weight of both male and female were around 60 to 70 $\mathrm{kg}$ and the range of age was around 40 to 50 years.

The tissues were labelled and subjected to histological processing. ${ }^{[34]}$ From each sample 9 slides were taken, out of which -3 slides were stained by haematoxylin \& eosin stain. 3 slides were stained by combined PAS-AB method. 3 slides were stained by Sudan Black B stain.

\section{IV. "RESULTS"}

Different histological findings were noted in the various layers of gall bladders of holelithiasis\&cholecystitis gall bladder which were compared with the normal gall bladders. In cholelithiasis samples the H\&E slides showed minimum and maximum break in continuity of epithelium in supranuclearpart. No goblet cells were found. Thehoney comb shape epithelial distortion noted. The sub-epithelial haemorrhagesnoted. Theepithelial dysplasia, hyperplasia and intactness also noted. The extensive damage of this layer was observed. Mucosa showed erosion and ramification. Maximum to minimum lymphocyte infiltration and lymphoid tissue proliferation were noted in successive layers. In case of cholelithiasis, the following changes were noted in muscular layer in H\&E slides, Normal pattern of epithelium were disturbed, multiple blood vessels with haemorrhages were found,The maximum infiltration lymphocytes and macrophages were noted. The extensive degeneration of villi, the lymphoid tissueand plasma cell proliferation were noted. RokitanskyAschoff sinuses were found which were seen to be invaginated from muscular layer to perimuscular 
layer. Serosa showed same finding as perimuscular layer with addition to minimum infiltration of lymphocytes and sub-serosal haemorrhages. After staining nuclei were found blue \& cytoplasm were found pink in H\&E stain. ${ }^{[35]}$ Staining with Sudan Black B simple lipid appeared bright red \& compound of other lipids appeared less strongly stained or unstained. ${ }^{[36]}$

PAS-AB slides were showed following statistical findings in case and control group-:

TABLE FOR CHOLELITHIASIS SAMPLES:-

\begin{tabular}{|c|c|c|c|c|c|}
\hline & & Sulfomucin & Sailomucin & Neutralmucin & Combinationmucin mucin \\
\hline \multirow[t]{5}{*}{ Epitheliu } & Case & 18 & 8 & 13 & 1 \\
\hline & Control & 1 & 1 & 43 & 1 \\
\hline & $\mathrm{OR}$ & 193.5 & 24.57 & 0.033 & 2.047 \\
\hline & Chi sq.\& & 41.47 & 11.72 & 14.15 & 0.064 \\
\hline & $\mathrm{P}$ value & 0.000 & 0.00061 & 0.00017 & 0.799 \\
\hline \multirow[t]{5}{*}{ Sub } & Case & 1 & 2 & 6 & 14 \\
\hline & Control & 1 & 1 & 43 & 1 \\
\hline & OR & 2.04 & 4.3 & 0.0087 & 75.25 \\
\hline & Chi sq.\& & 0.064 & 0.39 & 34.47 & 28.05 \\
\hline & $\mathrm{P}$ value & 0.799 & 0.53 & 0.000 & 0.000 \\
\hline \multirow{5}{*}{ 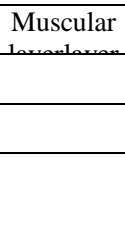 } & Case & 1 & 4 & 2 & 16 \\
\hline & Control & 1 & 1 & 43 & 1 \\
\hline & OR & 2.04 & 9.55 & 0.0023 & 114.66 \\
\hline & Chi sq.\& & 0.064 & 3.27 & 49.107 & 34.47 \\
\hline & $\mathrm{P}$ value & 0.799 & 0.070 & 0.000 & 0.000 \\
\hline \multirow{5}{*}{$\begin{array}{c}\text { Perimusc } \\
\text { ravise }\end{array}$} & Case & 1 & 1 & 5 & 17 \\
\hline & Control & 1 & 1 & 43 & 1 \\
\hline & OR & 2.04 & 2.04 & 0.006 & 146.2 \\
\hline & Chi sq\& & 0.064 & 0.064 & 37.89 & 37.89 \\
\hline & $\mathrm{P}$ value & 0.799 & 0.799 & 0.000 & 0.000 \\
\hline \multirow{4}{*}{$\begin{array}{c}\text { Serosal } \\
\text { r. }\end{array}$} & Case & 1 & 20 & 1 & 1 \\
\hline & Control & 1 & 1 & 43 & 1 \\
\hline & OR & 2.04 & 430 & 0.0011 & 2.04 \\
\hline & $\begin{array}{c}\text { Chi sq.\& } \\
\text { P value }\end{array}$ & $\begin{array}{l}0.064 \\
0.799\end{array}$ & $\begin{array}{l}49.10 \\
0.000\end{array}$ & $\begin{array}{l}53.19 \\
0.000\end{array}$ & $\begin{array}{l}0.064 \\
0.799\end{array}$ \\
\hline
\end{tabular}

*All finding of cases out of 22 and control out of 44 and OR represent the odds ratio

Table for Cholecystitis:-

\begin{tabular}{|c|c|c|c|c|c|}
\hline & & Sulfomucin & Sailomucin & Neutralmucin & Combinationmucin \\
\hline Epithelium & Case & 1 & 7 & 6 & 1 \\
\hline & Control & 1 & 1 & 15 & 1 \\
\hline & OR & 2.14 & 105 & 0.2 & 2.14 \\
\hline & Chi sq.\& & 2.66 & 7.38 & 0.24 & 2.66 \\
& P value & 0.102 & 0.0065 & 0.62 & 0.102 \\
\hline Sub mucosa & Case & 1 & 7 & 6 & 1 \\
\hline & Control & 1 & 1 & 15 & 1 \\
\hline & OR & 2.14 & 105 & 0.2 & 2.14 \\
\hline & Chi sq.\& & 2.66 & 7.38 & 0.24 & 2.66 \\
& P value & 0.102 & 0.0065 & 0.62 & 0.102 \\
\hline Muscular Layer & Case & 1 & 7 & 1 & 1 \\
\hline & Control & 1 & 1 & 15 & 1 \\
\hline & OR & 2.14 & 105 & 0.0095 & 2.14 \\
\hline & Chi sq.\& & 2.66 & 7.38 & 7.384 & 2.66 \\
& P value & 0.102 & 0.0065 & 0.00658 & 0.102 \\
\hline Perimuscular & Case & 1 & 6 & 2 & 1 \\
\hline
\end{tabular}


Histological Changes In Human...

\begin{tabular}{|c|c|c|c|c|c|}
\hline & Control & 1 & 1 & 15 & 1 \\
\hline & OR & 2.14 & 45 & 0.022 & 2.14 \\
\hline & Chi sq.\& & 2.66 & 4.766 & 4.7 & 2.66 \\
& P value & 0.102 & 0.029 & 0.029 & 0.102 \\
\hline Serosal Layer & Case & 1 & 6 & 2 & 1 \\
\hline & Control & 1 & 1 & 0.022 & 1 \\
\hline & OR & 2.14 & 45 & 4.7 & 2.14 \\
\hline & Chi sq.\& & 2.66 & 4.766 & 0.029 & 2.66 \\
& P value & 0.102 & 0.029 & 0.102 \\
\hline
\end{tabular}

*All findings of cases out of 8 and control out of 16 and OR represent the odds ratio.

PAS-AB slides were showed following histological findings-:

In combine PAS-AB stain the supra-nuclearand infra-nuclear part of the epithelium showed intense brownish blue colour suggestive of predominant sulfomucin and sailomucineffect ( $81.81 \%$ cases in cholelithiasis, $87.5 \%$ cases in cholecystitis).(Fig.1specified in figure legend).

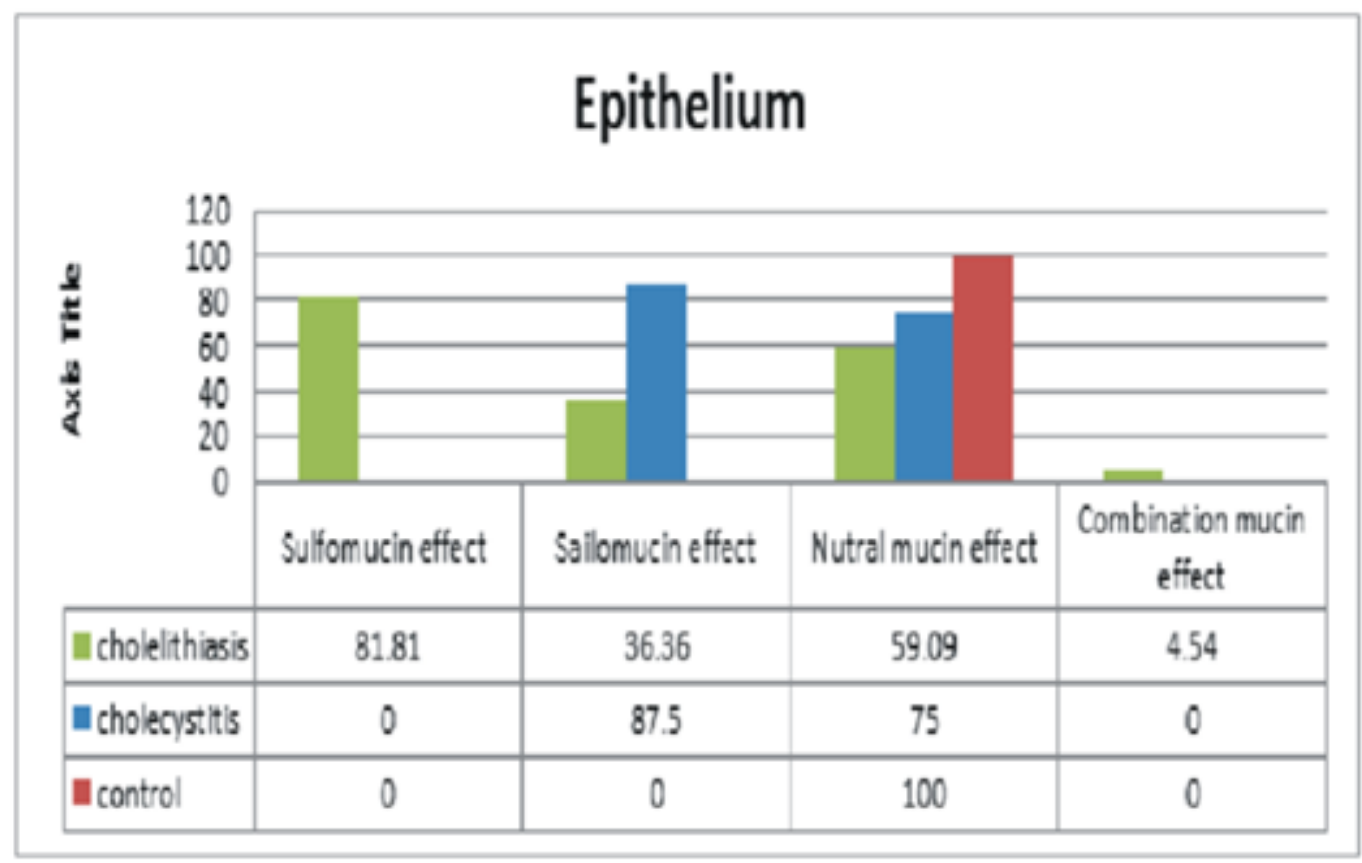

\section{1."bardiagram showing effect of sulfomucin,sailomucin,neutralmucin,combinationmucin in epithelium "Fig.1"}

On the behalf of statistical evidence, the present study shows both group case and control are highly significant. Sulfomucin is predominant variable for cholelithiasis ( $\mathrm{P}$ value 0.000 ) and sailomucin is predominant variable for cholecystitis ( $\mathrm{P}$ value 0.0065).The Relative Risk of patients in which sulfomucin present in epithelium layer or not present was 193:1(OR).According to this study it was found that the patients in which sulfomucin present were about 193 times as likely as patient in which sulfomucin absent to develop Cholelithiasis disease. As same forcholecystitis in which sailomucin present in epithelium and sub mucosa or not present was 105:1(OR).Deeper inside the epithelium, the mucosa and sub mucosashowed intense blue colour suggestive of predominantly sailomucineffect $(87.5 \%$ in cholecystitis). More deeper towards perimuscular\& serosa layer showed magenta red and weak blue colour suggestive of poor neutral mucin effect. Minimal goblet cells were seen with dark magenta in colour suggestive of poor neutral mucin effect. Some epithelia showed the mixture of magenta red and intense blue, suggestive of neutral mucin and sailomucineffect.(Fig.2specifiedinfigurelegend). 


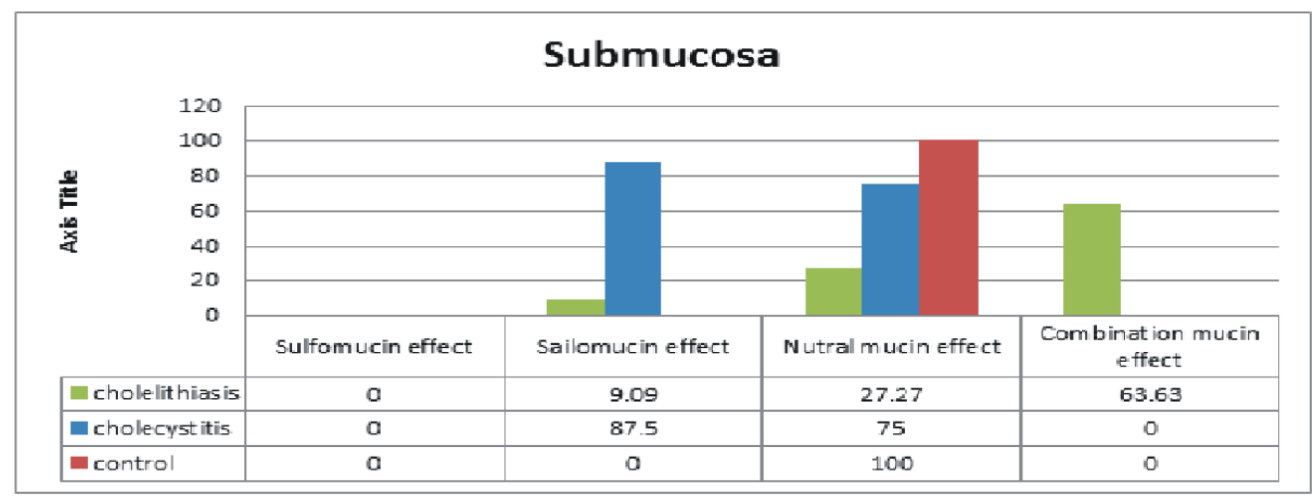

\section{2."bardiagram showing effect of sulfomucin,sailomucin,combinationmucin,neutralmucin in submucosa} "Fig.2"

Sub mucosa appeared weak blue, intense blue and magenta red suggestive of combination mucin effect in some and in other appeared intense blue suggestive of predominant sailomucin effect. (Fig.3 specified in figure legend).

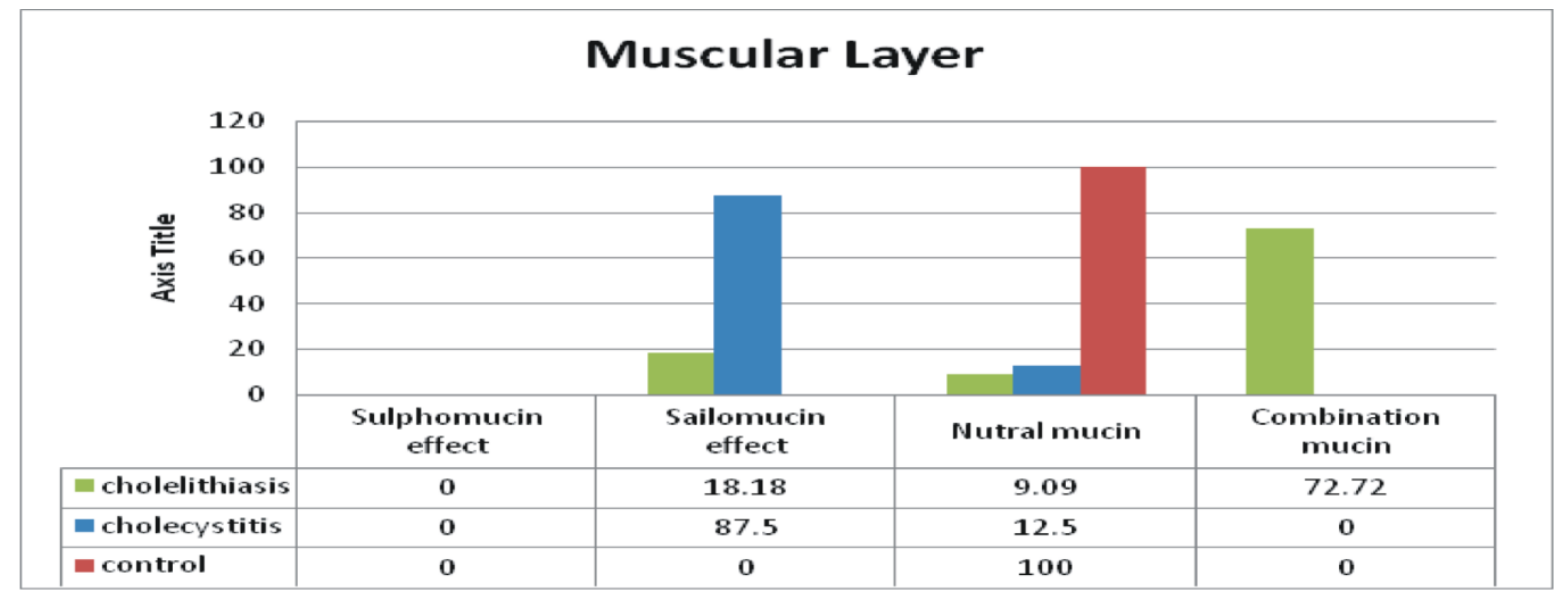

\section{3."bardiagram showing effect of sulfomucin,sailomucin,neutralmucin,combinationmucin in muscular} layer "Fig.3"

The same predominant variable is observed in muscular layer as observed in sub mucosa in cholecystitis cases. (Fig.4 specified in figure legend).

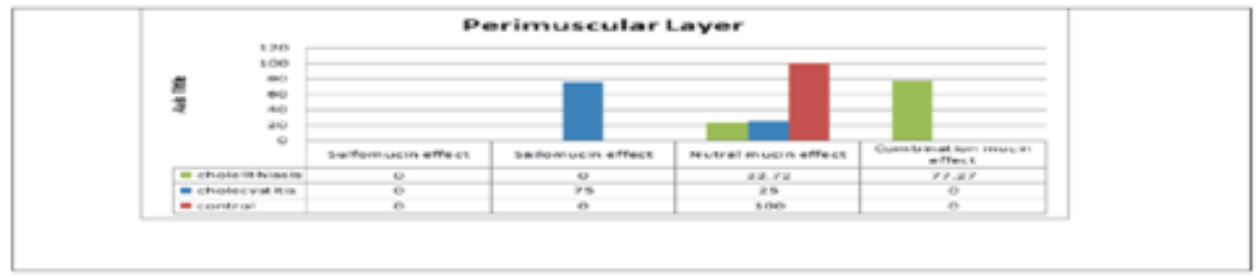

\section{4.“"bardiagram showing effect of sulfomucin,sailomucin,neutralmucin,combinationmucin in perimuscular layer "Fig.4"}

In cholelithiasis samples following changes were noted in perimuscular layer. The combine PAS-AB slides were showed same findings as seen in muscular layer. (Fig.5 specified in figure legend). 


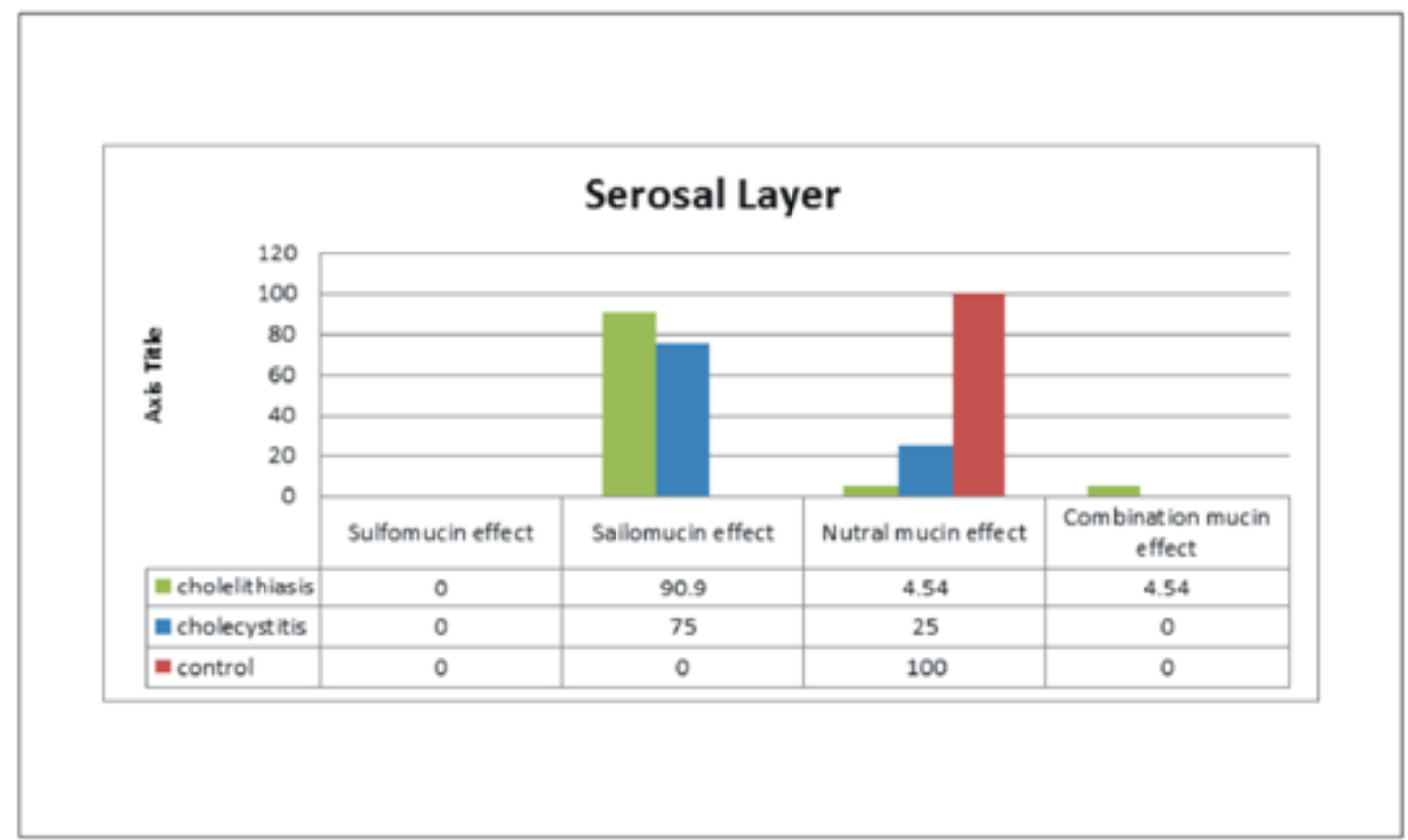

\section{5."bardiagram showing effect of sulfomucin,sailomucin,neutralmucin,combinationmucin in serosal layer "Fig.5"}

In cholelithiasis and cholecystitis samples following changes were noted in serosal layer. The combined PAS-AB slides showed intense blue stain which is suggestive of predominant sailomucineffect (90.9\% in cholelithiasis cases) and some showed magenta red \& intense blue which is suggestive of combination mucin effect. According to statistical evidence, the present study shows both group case and control are highly significant. sailomucin is predominant variable for cholelithiasis ( $\mathrm{P}$ value 0.000$)$.

The Relative Risk of patients in which sailomucin present in serosal layer or not present was 430:1(OR).According to this study it was found that the patients in which sailomucin present were about 430 times as likely as patient in which sailomucin absent to develop Cholelithiasis disease. More or less same odds ratio represents for serosal layer in cholecystitis cases. The Sudan Black B stained slides were showed blue black coloured epithelial lipids in supra nuclear part of epithelium, scattered lipid in sub mucosa and same epithelial lipid in rest of the layers.( Fig.6 \& Fig.7 specified in figure legend).

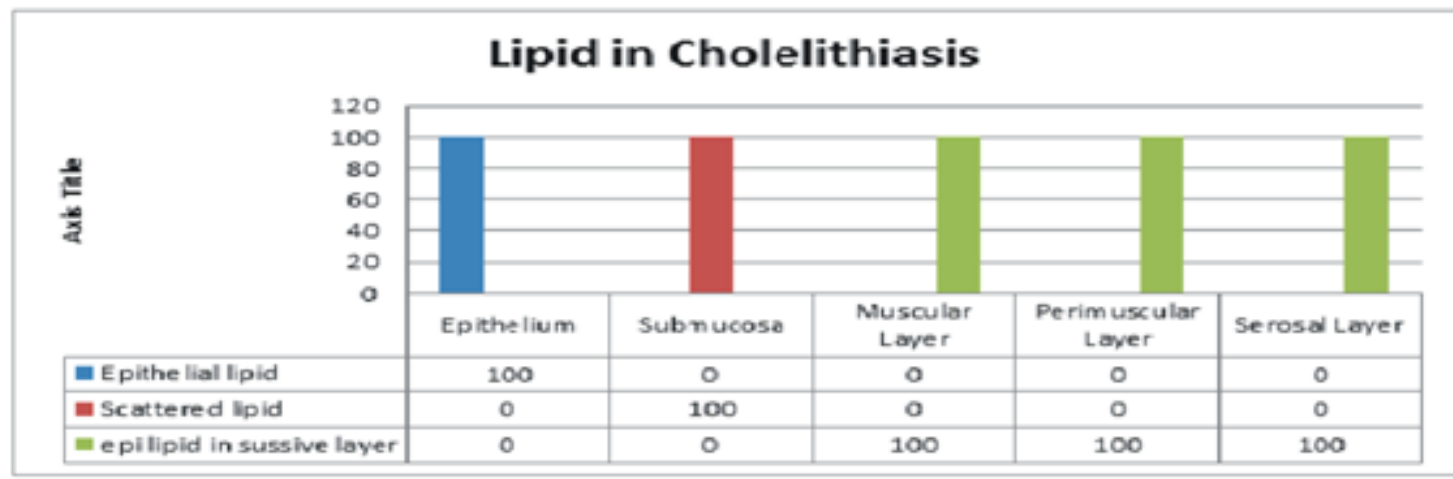

.'bar diagram showing percentage of epithelial lipid in all layers in cholelithiasishuman gallbladder"Fig.6" 


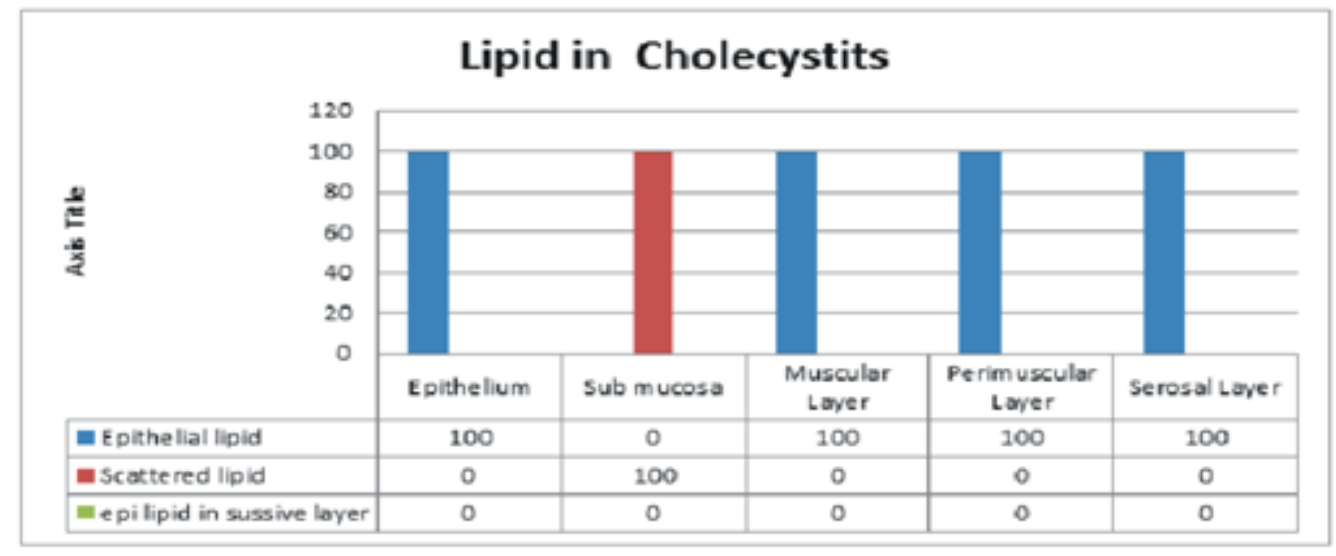

\section{7. “bar diagram showing percentage of epithelial lipid in all layers in cholecystitishuman gallbladder"Fig.7"}

More or less same effects were observed in cholecystitis samples in those successive layers. But the PAS-AB combined slides were showed predominantly neutral mucin in mucosa and sailomucin in other layers because colour appeared intense blue.

\section{DISCUSSION"}

In this present study 8 cholecystitis and 22 cholelithiasishuman gall bladders were studied histochemically by

1) H\&E stain (For routine histochemistry)

2) PAS-AB(Periodic acid Schiff stain and Alcian blue stain)(For mucin histochemistry)

3) Sudan black B(For lipid histochemistry)

The epithelial hyperplasia, dysplasia and/or epithelial distortion with erosion of mucosa in both cholecystitis and cholelithiasis. ${ }^{[3]}$ (Fig.8 specified in figure legend).

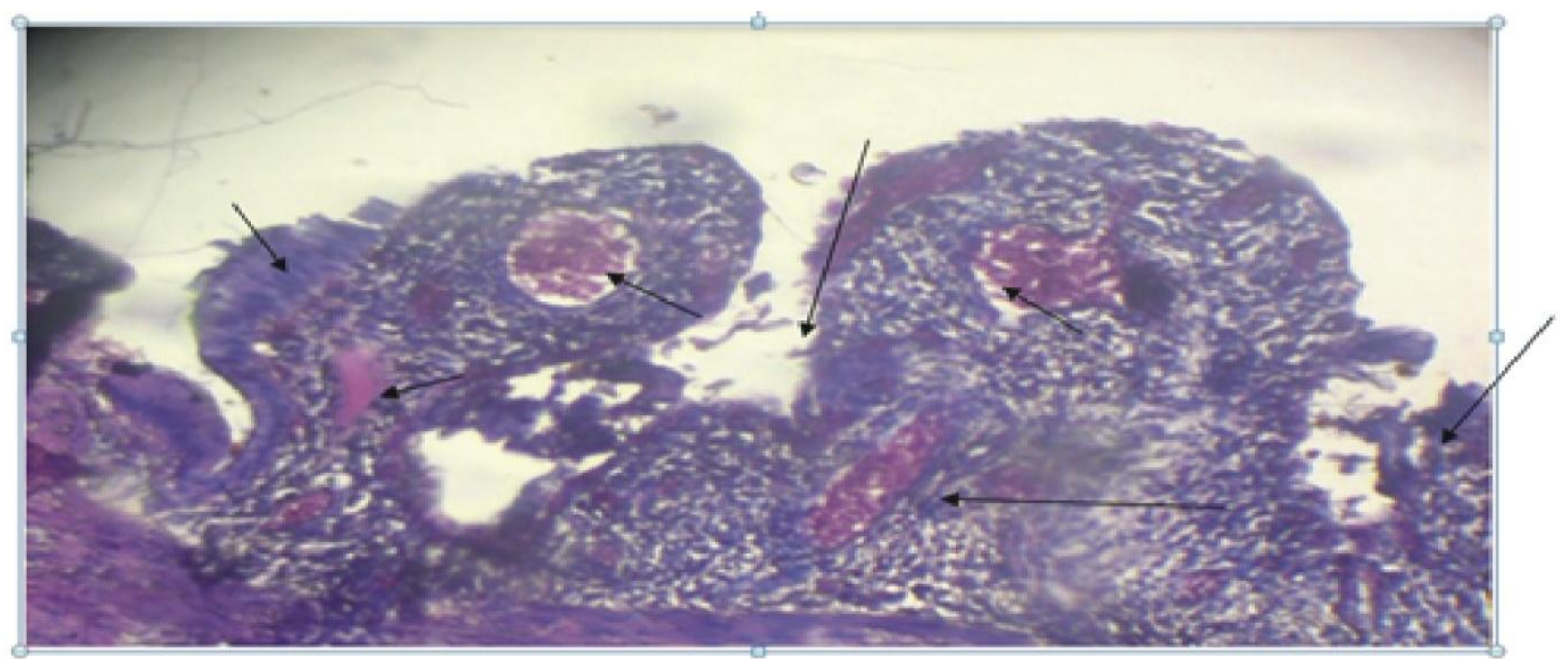

5.1. "lymphocytic infiltration and epithelial dysplasia"Fig.8"

In many cases it was associated withsub epithelial haemorrhages ${ }^{[12]}$ (Fig.9 specified in figure legend). 


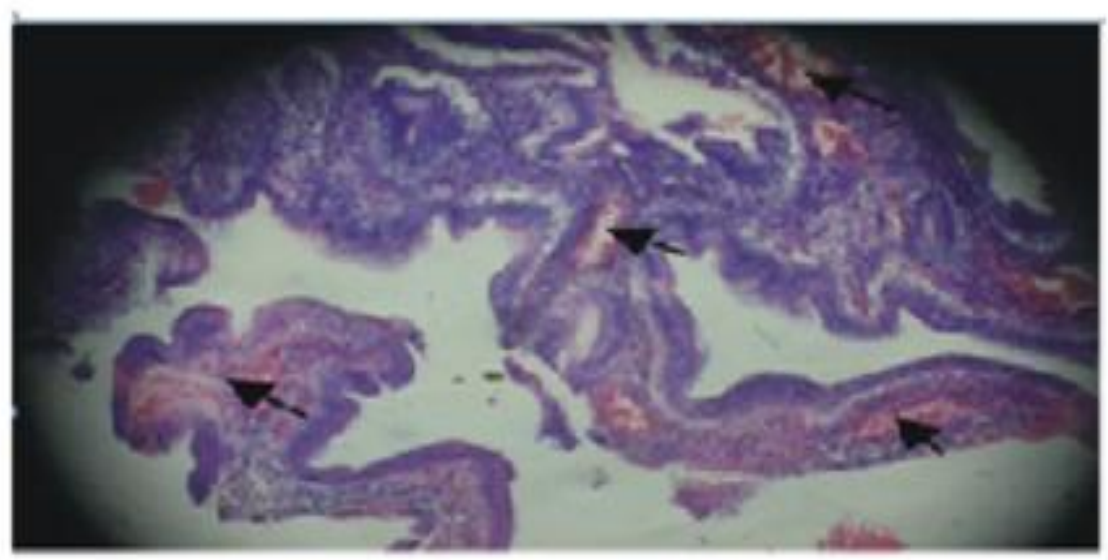

\section{2."subepithelial haemorrhages"Fig.9"}

In few cases they were even extending up to deep layers. Accumulated epithelial lipids were seen. Goblet cells were absent. The infiltrate was seen mainly in sub mucosa ${ }^{[13]}$ (Fig.8) (Fig.9).It extends up to muscular layer in few cases. It was focal and patchy in nature with presence of abundant lymphocytes and plasma cells ${ }^{[14]}$ (Fig.8). Multifocal dysplasia was seen ${ }^{[12]}$ (Fig.8). RokitanskyAschoff sinuses were seen in muscular layer. These were irregular gland like mucosal pockets extending deep into the thickened muscle layer ${ }^{[15,21]}$ (Fig.10 specified in figure legend).

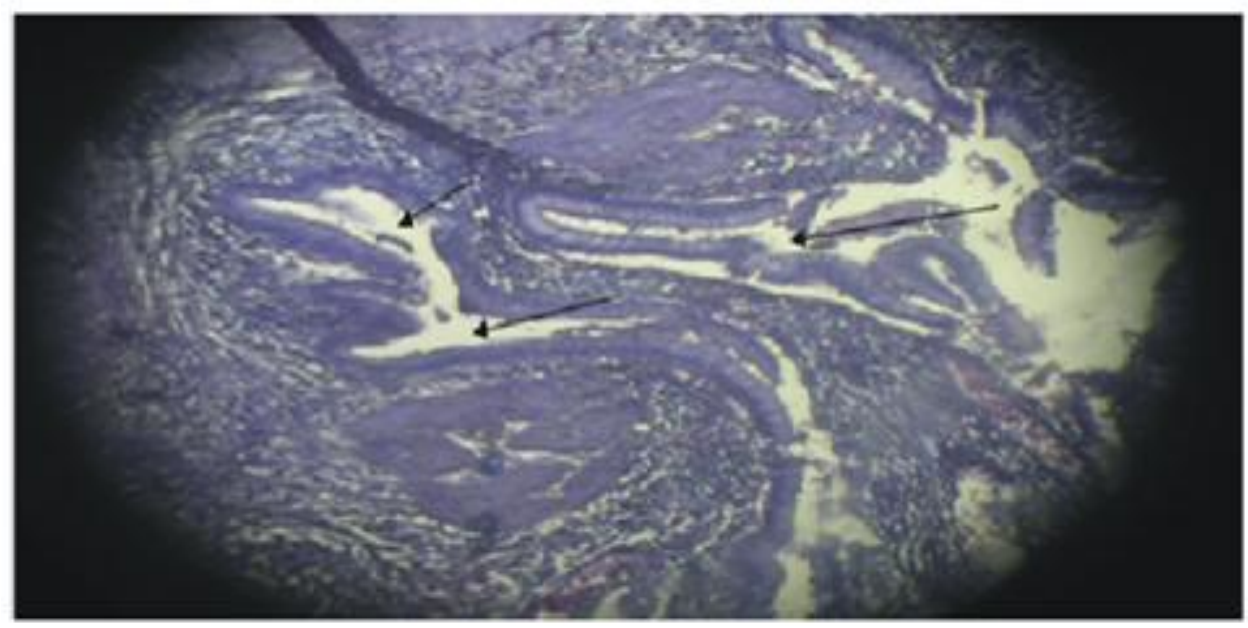

\section{3."rokitansky aschoff sinus"Fig.10"}

In normal gallbladder, expression of neutral mucin ispredominant ${ }^{[22-24,34]}$ (Fig.11 specified in figure legend).

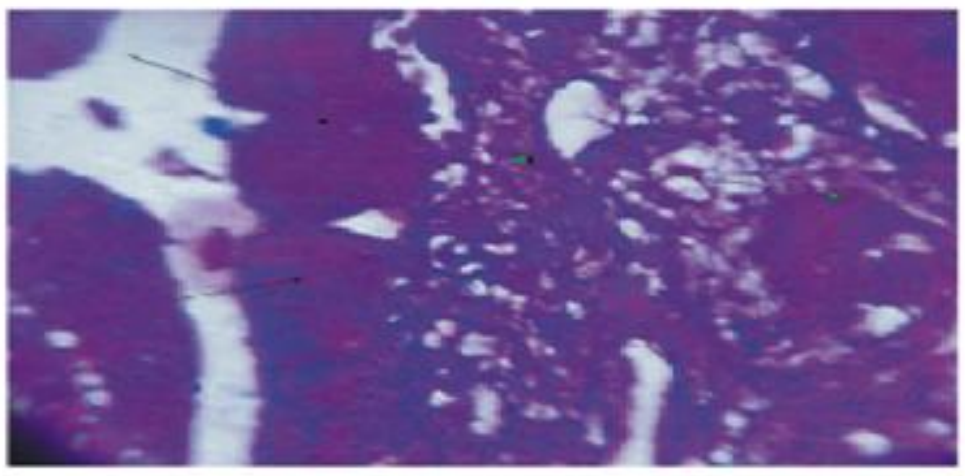

5.4."mucin histochemistry in normal gallbladder"Fig.11" 
In stone containing gallbladder sulfomucins and sailomucins are highly expressed. ${ }^{[34]}$ (Fig.12 specified in figure legend).

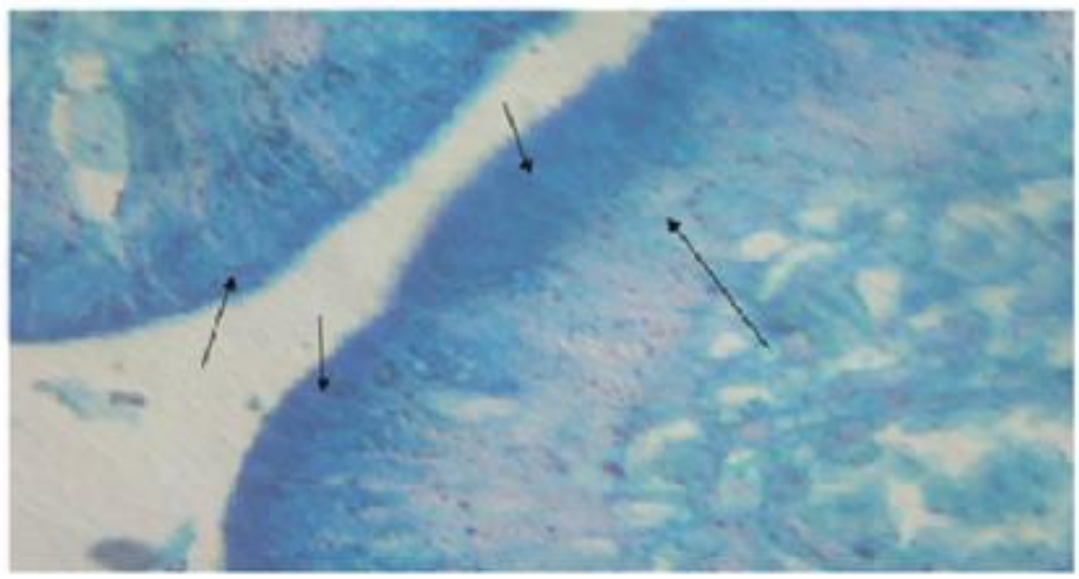

\section{5."mucin histochemistry in cholelithiasis gallbladder"Fig.12"}

Altered gall bladder bile supersaturated with cholesterol monohydrate crystals and impaired gallbladder functions are 3 major factors determining the formation of cholesterol gall stone. ${ }^{[25]}$ Nucleation of cholesterol monohydrate crystal is closely related to the concentration of mucus glycoproteins. ${ }^{[26]}$ How ever in black pigment stones which are devoid of cholesterol, the interaction of mucin, calcium and bilirubin is the sole mechanism for cholelithiasis. ${ }^{[27,29,30]}$ In this context the role of acid mucins, especially sulfomucins become more important to the formation of black pigment stones. ${ }^{[27]}$

In present study of the mucin histochemistry of cholelithiasis gall bladder it was found that sulfomucins were predominant in supranuclear region (Brownish blue by PAS-AB). In deeper partssailomucins were found (Intense blue by PAS-AB) and neutralmucin's were seen sparsely. (Magenta red of PAS-AB) (Fig.12). So present studies are comparable with similar study done by Halagowder D, Ganesh IM, Duraibabu S et al ${ }^{[35]}$.Incholecystitis gall bladder, neutral mucins was predominant than sailomucin. Neutral mucins were predominant in mucosa while in other layers sailomucins were predominant; sulfomucins were absent ${ }^{[24]}$ (Fig.13 specified in figure legend)

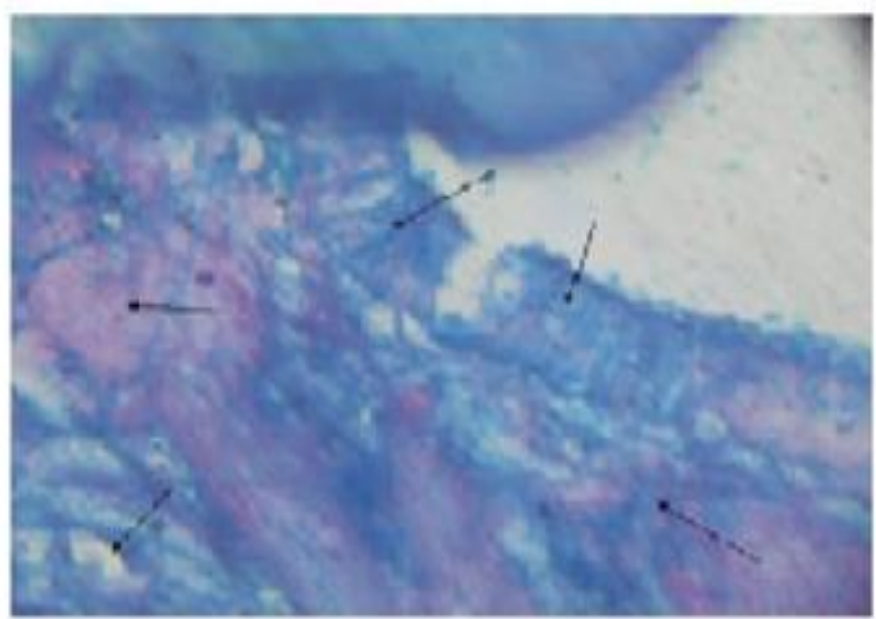

5.6."mucin histochemistry in cholecystitis gallbladder"Fig.13"

This is in accordance with the theory of stone formation. It is observed that $80 \%$ cholelithiasis is due to infection by bacteria. The centre of each gallstone has some bacteria and epithelial cells. It is said that gall stone is a tomb stone erected in the memory of the bacteria embedded in it. Most of the cholelithiasis is due to infection. In the present study, it was found that accumulation of phospholipidswas in epithelial cells predominantly in supranuclear region. ${ }^{[16,17]}$ (Fig.14 specified in figure legend). 


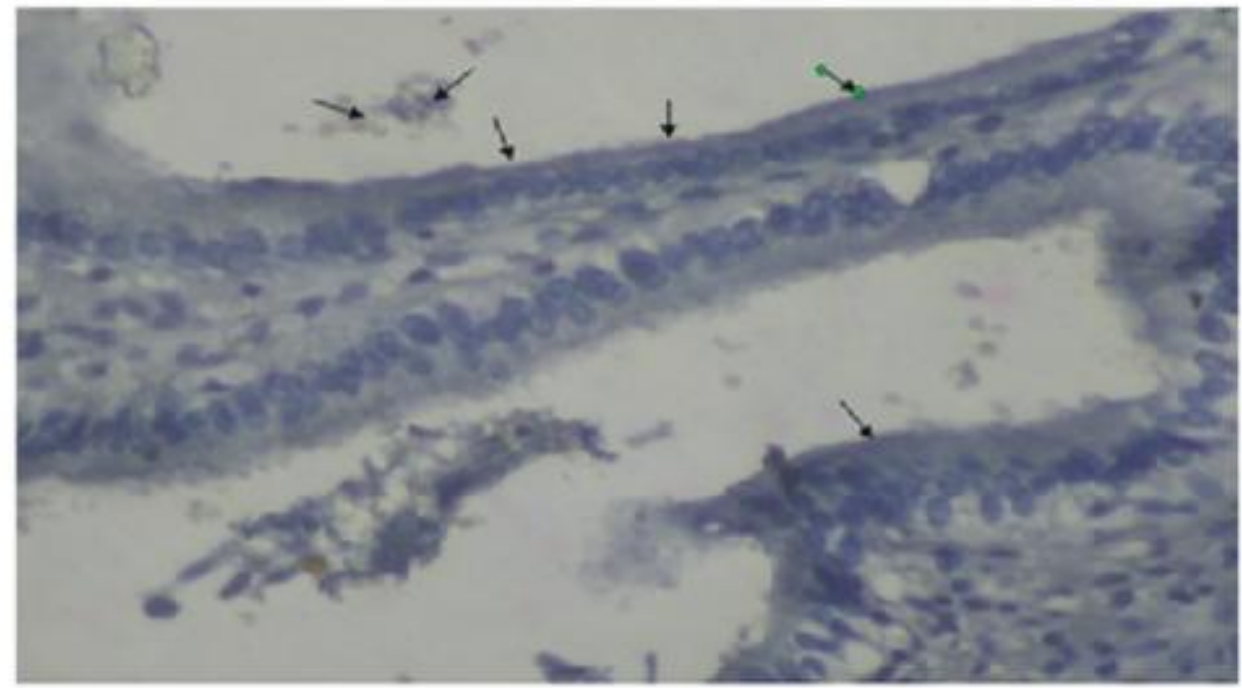

5.7."epithelial lipid in cholecystitis gallbladder"Fig.14”

Scattered lipids were found in other cells and tissues of gall bladder wall ${ }^{[17]}$ (Fig.14). These results are comparable with the result of Hopwood D, English M, Gilloteaux $\mathbf{J}$ et al ${ }^{[32,31]}$. Among the inflammatory changes seen in cholecystitis, the ultra-structural alteration of the human gall bladder epithelium includes lipid and lipofuscin deposits. The lipid is also deposited in other layers. Lipid load is further increased by epithelial debridement. Fusion of lipid deposits and mucus containing vesicles forming complex sub structural form called lipomucosomes. Epithelial cell sloughing could liberate and add mucins to the formation of biliary sludge and participate in gall stone formation. With chronic cholelithiasis fatty degeneration of scattered epithelial cells appear to alter the epithelial lining and favoursmetaplasticchange ${ }^{[18-20]}$. The new findings were assembled in the form of cell autophagy, mitochondrial autophagy and severe inflammation of smooth and rough endoplasmic reticulum, centrosome and death of lysosomal cells, ribosome along with ballooning degeneration of those cellular organelles in TEM view of epithelium of diseased gall bladder slides.

\section{CONCLUSION}

"In the present study an attempt is made to demonstrate the histological changes in cholecystitis and cholelithiasis gall bladders. The main purpose was to evaluate the usefulness of mucin in understanding the gall stone formation \& demonstration of phospholipids in the human gall bladder mucosa. The basic principle in gall stone formation is accumulation of lipids and hyper secretion of acidic mucin. Particularly sulfomucin have major role in gall stone formation. Once these changes occur, they alter the normal tissue pattern \& can induce carcinogenic progression \& metastasis. Blockage of mucin release can prevent gall stone formation in high risk patients or during high risk period. This finding suggests that inhibition of mucin release may prevent stone formation. ${ }^{[28]}$ The compounds which can regulate sailylation and sulfation might help to inhibit gall stone formation $\&$ metastasis. This needs further study as it can open up an entirely new therapeutic approach. The advantages of this work is that the diseased world will be able to get the benefit of an effective drug which will be able to prevent carcinoma gall bladder by preventing sulfation and sailylation.Because prevention is better than cure. If the clinician investigates a case of cholecystitis or cholelithiasis definitely he or she must start the effective drug in this condition in order to prevent carcinoma gallbladder. Limitation is still adequate study not done in this line. Possible application is on the clinical field to prevent fatal disease like carcinoma gall bladder in human being.

\section{ACKNOWLEDGEMENT} future.

I acknowledge all my co-authors and my reviewers for my study and wish them all the best for the

\section{CONFLICT OF INTEREST"}

There is no conflict of interest between me and my co-authors. I ensure that tables are cited in the main text of my paper. I got the study approval from local ethical committee of M.G.M. Medical College, KamotheNavi Mumbai for my paper. Review of literature is mentioned in this manuscript because most of the references are cited in body of the review of literature. 


\section{REFERENCES-:}

[1.] MohanH,Extra Hepatic Biliary Apparatus-Gall bladderin (5th Edition),Text Book of Pathology, 19, 658-664, 2005).

[2.] Carey MC,Pathogenesis of gall stone,Am J. Surg,165, 1993,410-410.

[3.] Sherlock S,Diseases of the liver and biliary system(Blackwell Scientific Publication, Oxford. 10th Edition, 1-714, 1997).

[4.] Dussek JE, Bannister LH , Barry MM, et al(Gray's Anatomy

[5.] IN: Nervous system. Chapter12,Churchill

[6.] Livingston Edinburgh.,38th Edition, 1795-1812, 140,141,1810-1812,144,155-160, 2010).

[7.] FleischnerFG, Sayegh V,Assessment of the size of the liver, Roentgenologic consideration,New England Journal of Medicine,Med 259, 1958,271-274

[8.] Meilstrup ^J.Imaging atlas of normal gall bladder and its variants. CRC Press (an imprint of Taylor \& Francis group) Boca Raton FL].pp.4.ISBN/0-8493-4788-2.

[9.] DifioreSH, Mariano,The digestive system, the accessory digestive organs(7th Edition), Gallbladder Organ's section Atlas of Histology, 7, 204-205, 2009).

[10.] SinghIB,Extra hepatic biliary apparatus Gall bladder (5th Edition), Text book of human histology with colour atlas, 16,259-260, 2006

[11.] ChiardoAJ, Chapman GB andWeinekeK et alThe fine structure of mucosal epithelial cell of a pathological human gallbladder. Anat Rec, 12.155, 1966, 579-616.

^"Slide5:GallBladder"JaydochistoWeb.University

Kankas.http://www.kumc.edu/instruction/medicine/anatomy/histoweb/epithel/epith05.htm.Retrieval of on. 2007:06-29.

PatholAnatfür, И, 1857, 574-578.

$$
\text { 336-337. }
$$

Wallraff J, Dietrich KF,Morphologie Histochemie der Stein gallen blasé des Menschen,Clin. Chim. Acta, 46, 1957,155-231.

Schwartz SI, Dale WA,Primary Sclerosing Cholangitis: A review and report of six cases,Arch Surg, 77, 1958,350-439.

Thorpe MEC, Scheuer PJ, Sherlock S, et alPrimary sclerosing cholangitis with biliary tree \& ulcerative colitis, gut, 1967,435-448.

Hopwood D, Kouroumalis E, Milne G, et al Cholecystitis: a fine structural analysis,J. Pathol, 130, 1980,1-13.

Baylis High OB.Lipid in: Bancroft JD, Stevens A, et al Ch12, Theory and practice of Histological Technique,Churchill living stone, Edinburgh,2nd Edition, 1982,217-241

[20.] Smith BF, Moore JRL, Lamont JT, et alRole of gall bladder mucin in pathophysiology of gall stone, Hepatology, 3, 1984, 377382.

[21.] Hopwood D, English M,Lipid in human gall bladder mucosa A histochemical study by light and electron microscopy, JPathol,146, 1985,333-336.

[22.] Pearson JF, Foster NE,Mucus glycoproteincontent of human cholesterol gall stone,Journal of Digestion, 36, 1987, 132-140.

[23.] Tami Yama H,Yamigiwa H.Intestinal metaplasia - Dysplasia carcinoma sequence of the gallbladder. ActaPathol. JPN. 1987,36:989-997.

[24.] AfdhalNH,Cholesterol crystal nucleation: A decade long search for the missing link in gall bladder pathogenesis, Hepatology.1, 1990,669-702.

[25.] Jeffrey GP, Shilkin KB, Carrello S, et al Histological and immunohistochemical study of the gallbladder lesion in primary sclerosing cholangitis, gut, 1991, 32, 424-429.

[26.] Badke A,Böhm B,SchwenkW, et alHistopathological changes of gall bladder and liver parenchyma in symptomatic cholelithiasis. Dtsch med Wschr,118,Issue:22,Jun4, 1993,809-813.

[27.] Gilloteaux J, Karkare S, Kelly TR et alUltra structural aspect of human gall bladder in cholelithiasis: production of anionic mucus, Microsc Res. Tech,38, 1997,653-659.

[28.] Hernandez F,Ballesta J, Madrid JF,et alCharacterisation of glycoprotein in the epithelial cell of human and other mammalian gall bladder, Microsc Res. Tech,38, 1997,616-630.

[29.] Csendes A, Maluenda F, Smok G, et alHistological findings of gall bladder mucosa in 95 control subjects and 80 patients with asymptomatic gall stones,Journal of Digestive diseases and sciences,43, 1998,931-934

[30.] Y.-E, Lee KT, Sheen PC,et alMucin content in with brown pigment stones or Combination stones with a Brown Periphery,Journal of Digestion,59,6, 1998,660-664.

[31.] ElgisonDA, TomaselloLM,GilloteauxJ,et alLipid deposits and Lipo-mucosomes in Human cholecystitis and Epithelial Metaplasia in Chronic Cholecystitis,Journal of Ultra structural pathology,27, 2003, 313-321.

[32.] HopwoodD, EnglishM, et alLipid in human gall bladder mucosa a histochemical study by light and electron microscopy, J.Pathol, 146,4, 2005,333-336.

[33.] Halagowder Dc, SubramaniDob,GaneshIMa,et al Mucin glycoarray in gastric\& gallbladder epithelia. Carcinogenesis,6, 2007,16.

[34.] GaneshIM, JacynaMR. Mucin histochemistry of stone-containing gall bladder epithelium....Interaction between gall bladder bile and mucosa,Carcinogenesis, 6, 2007,6-29.

[35.] SmithBF, LamontJT, Moore JRL, et alRole of gall bladder mucin in pathophysiology of gall stones, The Journal of the American Medical Association,4, 2008,51S-56S.

[36.] WallingtonEA, DruryRAB,Method to prepare Combined PAS-AB stain and Sudan Black B stain,Carlton's Histological techniques, 5th edition, Chapter: 3, 4, 7, 13, 15, 36-56, 57-75,125-150,232-259,285-297.

[37.] JefferyGP,CarrelloS, ReedWD, et alHistological and immunohistochemical study of the gallbladder lesion in primary sclerosing cholangitis. Gut,32,1991,424-429.

[38.] LudwigJ,Surgical Pathology of the syndrome of primary sclerosing cholangitis,Am J SurgPathol,9, 1989,43-49.

\section{FIGURE LEGENDS-:}

[1.] Figure1 represents bar diagram to show percentages of sulfomucin,sailomucin and combination mucin effect in epithelium of human gallbladder in cholelithiasis, cholecystitis and control samples for comparison.

[2.] Figure 2 represents bar diagram to show percentages of sulfomucin, sailomucin and combination mucin effect in sub mucosa of human gallbladder in cholelithiasis, cholecystitis and control samples for comparison.

[3.] Figure 3 represents bar diagram to show percentages of sulfomucin, sailomucin and combination mucin effect in muscular layer of human gallbladder in cholelithiasis, cholecystitis and control samples for comparison. 
[4.] Figure 4 represents bar diagram to show percentages of sulfomucin, sailomucin and combination mucin effect in perimuscularlayer of human gallbladder in cholelithiasis, cholecystitis and control samples for comparison.

[5.] Figure 5 represents bar diagram to show percentages of sulfomucin, sailomucin and combination mucin effect in serosallayer of human gallbladder in cholelithiasis, cholecystitis and control samples for comparison.

[6.] Figure 6 represents bar diagram to show percentages of lipid in all layer of human gallbladder in cholelithiasis for comparison.

[7.] Figure 7 represents bar diagram to show percentages of lipid in all layer of human gallbladder in cholecystitis for comparison.

[8.] Figure 8 represents lymphocytic infiltration and epithelial dysplasia in both.

[9.] Figure 9 represents lymphocytic sub-epithelial haemorrhages in both.

[10.] Figure 10 represents RokitanskyAschoff sinuses in muscle layer in cholelithiasis.

[11.] Figure 11 represents neutral mucin in normal gallbladder.

[12.] Figure 12 represents mucin histochemistry in cholelithiasis.

[13.] Figure 13 represents mucin histochemistry in cholecystitis.

[14.] Figure 14 represents epithelial lipid incholecystitis. 